\title{
The Performance Test and Application in Shaped Charge of Heat Resistance Explosive LLM-105
}

\author{
Li Bi-Hong \\ Research and Development Center \\ Xi'an WuHua Juneng Blasting Equipment CO., LTD. \\ Xi'an, Shaanxi, China \\ 6160946@qq.com
}

Li Shang-Jie

Research and Development Center

Xi'an WuHua Juneng Blasting Equipment CO., LTD.

Xi'an, Shaanxi, China

zbdx04081401@163.com

\author{
Zhao Yun-Tao \\ Research and Development Center \\ Xi'an WuHua JuNeng Blasting Equipment CO.,LTD \\ Shaanxi Xi'an, China \\ zyt21305@126.com \\ Li Zhe-Yu \\ Research and Development Center \\ Xi'an WuHua JuNeng Blasting Equipment CO.,LTD \\ Shaanxi Xi'an, China \\ lzy21305@126.com
}

\begin{abstract}
In order to guarantee the safety and reliability on the operation of oil and gas well, tested the thermal stability, mechanical sensitivity, flame sensitivity, electrostatic spark sensitivity and the 5s delay explosion temperature of LLM105 explosive. And conducted the tests with 4 1/2 " perforating charge loaded mixed LLM-105 under the temperature of normal, $220^{\circ} \mathrm{C} / 100 \mathrm{~h}$ and $220^{\circ} \mathrm{C} / 2 \mathrm{~h} / 20 \mathrm{Mpa}$ conditions. Contrasted with the perforating deep test results of perforating charge loaded S992、Y971 on normal temperature. The test results show that the thermal stability of LLM-105 is stable, DSC maximum exothermic peak up to $360.02{ }^{\circ} \mathrm{C}$, impact sensitivity is $42 \%$, friction sensitivity is $16 \%$,flame sensitivity is $0 \%$,electrostatic spark sensitivity is low and no obvious ignition, the $5 \mathrm{~s}$ delay explosion temperature is $387^{\circ} \mathrm{C}$, so LLM-105 is an excellent insensitive heat-resistant explosive, the steel target perforating deep results of 4 1/2 " perforating charge loaded LLM-105 show that the average penetration depth are respectively $256.3 \mathrm{~mm}$ and $254.7 \mathrm{~mm}$ on normal temperature and $200{ }^{\circ} \mathrm{C} / 100 \mathrm{~h}$ condition. The perforating deep results of API columnar concrete targets show that the average penetration depth of charge loaded LLM-105 is $922.5 \mathrm{~mm}$ on $220{ }^{\circ} \mathrm{C} / 2 \mathrm{~h} / 20 \mathrm{Mpa}$ condition. the steel target perforating deep of $41 / 2$ " charge loaded LLM-105 increased $25.3 \%$ than charge loaded S992, increased $36.7 \%$ than charge loaded Y791 on normal temperature condition.
\end{abstract}

Keywords-insensitive; heat-resistance; LLM-105; sensitivity; safety property; shaped charge

\section{INTRODUCTION}

With the development of oil and gas resources exploration and development unceasingly thorough, the extreme region of deep, ultra deep, deep and ultra-deep sea has become an important field of oil and gas exploration, the formation mainly have high temperature and high pressure, low permeability, high density; therefore put forward higher requirements on the technology of well completion, in order to meet the requirement of safety and reliability in deep oil and gas development, the perforation equipment must have higher perforating deep performance and safety reliability.

The LLM-105 is an excellent energetic materials that has high energy density and low sensitivity, 1993 America Lawrence Livermore National Laboratory (LLNL) the first synthesis [1], the energy is $15 \%$ higher than TATB , it is very stable to heat and mechanical effect, the temperature of thermal analysis can reach more than $350^{\circ} \mathrm{C}$. It had been concerned and begun to synthesis and characterization research by the international explosives community in 1998 [2-6], various domestic research institutes started synthesis and performance researched of LLM-105 in 2003 [7-9], the LLM-105 is an ultra-high temperature explosive has the prospects for development.

In order to ensure the safety and reliability of operation, this paper studied the related safety of LLM-105 explosive, and tested perforating performance contrast with charge loaded S992, Y971. At the same time, according to the actual situation of the operation of oil and gas wells, have tested heat resistance of perforating charge loaded LLM105 explosive in different temperature which can provide some reference basis to expand the application of LLM105 in oil and gas field in future.

\section{EXPERIMENTAL MATERIALS}

In this paper, the use of materials are: Based on LLM105 mixed explosives L091, based on HNS mixed explosives S992, based on PYX mixed explosive Y971. The part performance of the L091, S992, Y971 such as shown in Table I. 
TABLE I. COMPARISON OF THE PROPERTY OF L091、S992 AND Y971

\begin{tabular}{|c|c|c|c|}
\hline Material & $\begin{array}{c}\text { Density/ } \\
\mathbf{g} \cdot \mathbf{c m}^{-\mathbf{3}}\end{array}$ & $\begin{array}{c}\text { Detonation } \\
\text { velocity/m } \cdot \mathbf{s}^{-\mathbf{1}}\end{array}$ & $\begin{array}{c}\text { Formulation/ } \\
\mathbf{\%}\end{array}$ \\
\hline L091 & 1.726 & 7680 & $96.5 / 3.5$ \\
\hline S992 & 1.607 & 6879 & $96.2 / 3.8$ \\
\hline Y971 & 1.625 & 6839 & $95.5 / 4.5$ \\
\hline
\end{tabular}

\section{THE PERFORMANCE TEST OF THE EXPLOSIVE}

The thermal analysis research has important significance to the production and use of explosive, in this paper, the safety performance of LLM105 has been tested and analyzed by means of differential scanning calorimetry (DSC), impact sensitivity, friction sensitivity, flame sensitivity, electrostatic spark sensitivity and the 5s delay explosion temperature.

\section{A. Thermal stability test of LLM105}

Instruments: DSC204F1 differential thermal analyzer made by Netzsch Company in Germany. Its heating rates are: $5{ }^{\circ} \mathrm{C} / \mathrm{min} 、 10^{\circ} \mathrm{C} / \mathrm{min} 、 15^{\circ} \mathrm{C} / \mathrm{min}$ 和 $20^{\circ} \mathrm{C} / \mathrm{min}$. The DSC curves of LLM-105 under different experimental conditions were showed in Fig . 1 - Fig . 4.

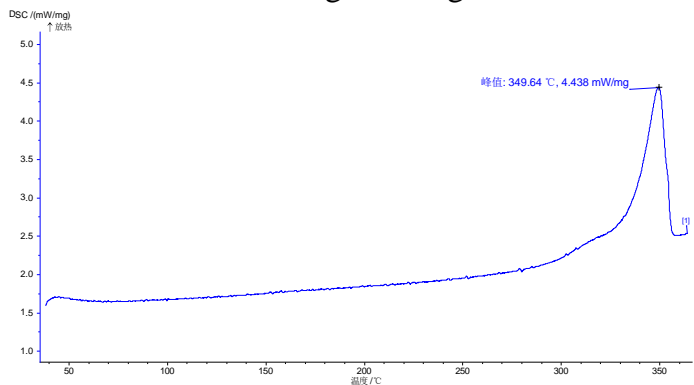

Figure 1. DSC curve by $5^{\circ} \mathrm{C} / \mathrm{min}$

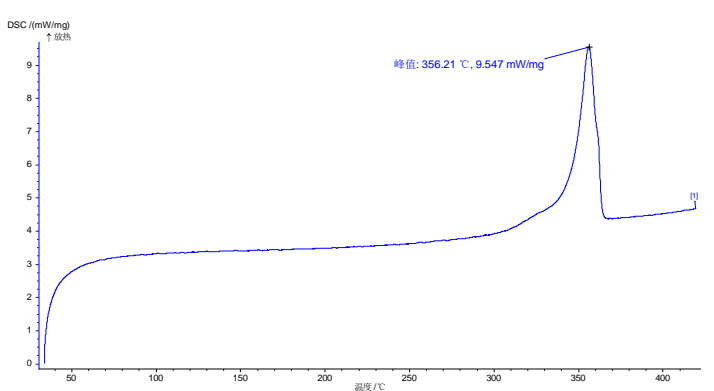

Figure 2. DSC curve by $10^{\circ} \mathrm{C} / \mathrm{min}$

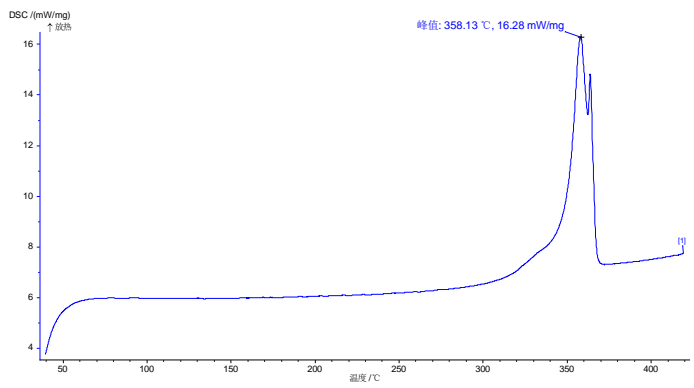

Figure 3. DSC curve by $15^{\circ} \mathrm{C} / \mathrm{min}$

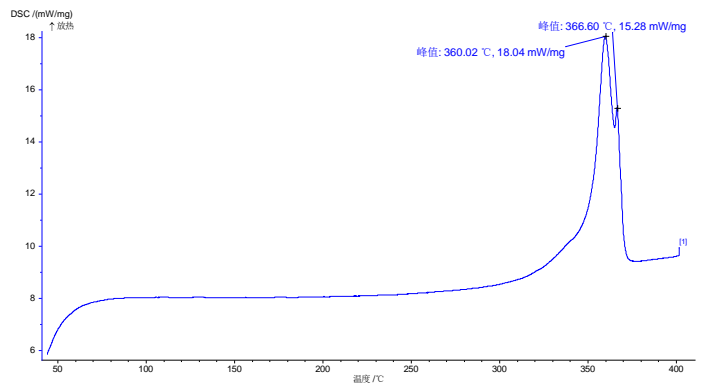

Figure 4. DSC curve by $20^{\circ} \mathrm{C} / \mathrm{min}$

According to figure from figure 1 to 4 , by different heating rates, onset temperatures for decomposition of LLM-105 are $349.64{ }^{\circ} \mathrm{C} 、 356.21{ }^{\circ} \mathrm{C} 、 358.13{ }^{\circ} \mathrm{C}$ and $360.02{ }^{\circ} \mathrm{C}$.It showed that LLM-105 has excellent heat resistance.

\section{B. Impact sensitivity of LLM-105}

Measured by Custer impact sensitivity apparatus, with GJB772A-97 testing method: $50 \mathrm{mg}$ dose, $10 \mathrm{~kg}$ hammer, $25 \mathrm{~cm}$ drop height, testing number 50 . The result is shown in Table II.

TABLE II. IMPACT SENSITIVITY OF LLM-105

\begin{tabular}{|c|c|}
\hline Material & LLM-105 \\
\hline Probability of explosive (P \%) & 42 \\
\hline
\end{tabular}

\section{Friction sensitivity of LLM-105}

Using the friction pendulum to measure its friction sensitivity, with GJB772A-97 testing method: $80^{\circ}$ swing angle, $3.43 \mathrm{Mpa}$ pressure, $20 \mathrm{mg}$ dose, testing number 50. The result is shown in Table III.

TABLE III. FRICTION SENSITIVITY OF LLM-105

\begin{tabular}{|c|c|}
\hline Material & LLM-105 \\
\hline Probability of explosive $(\mathrm{P} \%)$ & 16 \\
\hline
\end{tabular}

\section{Flame sensitivity of LLM-105}

Using the flame sensitivity instrument to measure its flame sensitivity, with GJB772A-97 testing method: testing number $25,20 \mathrm{~mm}$ ignition distance. The result is shown in Table IV.

TABLE IV. FLAME SENSITIVITY OF LLM-105

\begin{tabular}{|c|c|}
\hline Material & LLM-105 \\
\hline Probability of explosive (P \%) & 0 \\
\hline
\end{tabular}

E. Electrostatic spark sensitivity of LLM-105

With GJB5891.27-2006 static spark sensitivity testing method: $25 \mathrm{mg}$ dose, test number $30,3.0 \sim 7.0 \mathrm{kV}$ charging voltage, $0.22 \mu \mathrm{F}$ electric capacity, $1000 \Omega$ series resistor.

The result pointed out that although charging to $0.22 \mu \mathrm{F}$ capacitor by $7.0 \mathrm{kV}$, there was no obvious ignition phenomenon.

\section{F. The 5s delay explosion temperature of LLM-105}

Using BDF-1 flash point tester, with GJB5891.20-2006 Pyrotechnics pharmaceutical test methods, the $5 \mathrm{~s}$ delay explosion temperature of LLM-105 was tested. Table V is flashpoint test data. 
TABLE V.

THE 5S DELAY EXPLOSION TEMPERATURE OF LLM-105

\begin{tabular}{|c|c|c|}
\hline Material & Temperature(K) & Delay time(s) \\
\hline \multirow{4}{*}{ LLM-105 } & 655 & 6.01 \\
\cline { 2 - 3 } & 661 & 5.04 \\
\cline { 2 - 3 } & 664 & 4.31 \\
\cline { 2 - 3 } & 668 & 3.44 \\
\cline { 2 - 3 } & 671 & 2.89 \\
\hline
\end{tabular}

The delay explosion $\tau$ and temperature of explosion $\mathrm{T}$ uses the following equations of state, in the form:

$$
\begin{gathered}
\tau=c e^{\frac{E}{R T}} \\
\ln \tau=\frac{E}{R T}+\ln c
\end{gathered}
$$

where $\tau$ is the value of delay explosion in $\mathrm{s}, \mathrm{c}$ is a constant related the tested material component, $\mathrm{E}$ is the values of apparent activation energy of the tested material in $\mathrm{J} / \mathrm{mol}, \mathrm{R}$ is gas constant of $\operatorname{molar}(8.314 /(\mathrm{mol} \cdot \mathrm{K}))$, $\mathrm{T}$ is values about temperature of explosion in $\mathrm{K}$.

Fig .5 showed the analysis of the data in Table V.

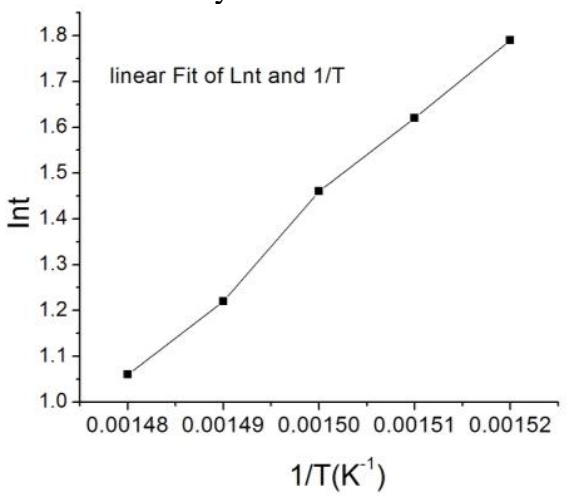

Figure 5. Relations of lnt versus $1 / \mathrm{T}$

After the linear regression processing to data in Table. $\mathrm{V}$, the 5 s delay explosion temperature of LLM-105 is $660 \mathrm{~K}$ or $387^{\circ} \mathrm{C}$.

\section{APPLICATION AND RESULTS OF THE ANALYSIS OF LLM-105}

After a series of tests about the safety of LLM-105, in this paper, the explosive mixture L091 which is based on LLM-105 was used for the main charge of shaped charge. Then researched the performance varieties of penetrating on steel target by simulated ground guns under different conditions of normal temperature, $220^{\circ} \mathrm{C} / 100 \mathrm{~h}$ and also under the conditions of $220^{\circ} \mathrm{C} / 2 \mathrm{~h} / 20 \mathrm{MPa}$ to penetrate API cylindrical concrete target. At the same time, carried out contrast tests by using explosive mixtures S992 which is based on HNS and PYX based on Y971 as the main charge of shaped charges penetrating on steel targets under normal temperature. The diameter of the guns is $41 / 2$ "

\section{A. Penetrating tergat in condition of normal temperature}

Under normal conditions the LLM-105 mixed explosives packed in $41 / 2 "$ type perforated shells, the loading dose $38 \mathrm{~g}$, conduct ground simulation equipment 4 $1 / 2$ " steel target type guns wear test, the test assembly drawing as Fig .6, the test results are shown in Table VI.
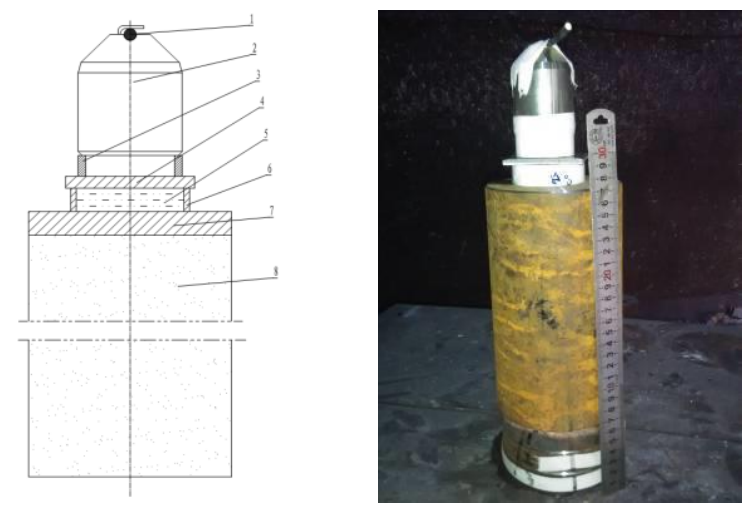

1-blasting fuse 2 - perforating charge 3-High-burst inside gun 4 gun 5-water 6-High-burst outside gun 7-casing pipe 8-target

Figure 6. Schematic diagrams of penetrating tergat in condition of normal temperature

TABLE VI. PENETRATING TERGAT USING 4 1/2 " GUN IN CONDITION

\begin{tabular}{|c|c|c|c|c|}
\hline Sample & Power & $\begin{array}{l}\text { casing } \\
\text { pipe }\end{array}$ & $\begin{array}{c}\text { Penetrating/ } \\
\text { mm }\end{array}$ & $\begin{array}{c}\text { Pore size of } \\
\text { casing pipe/mm }\end{array}$ \\
\hline 1 & \multirow{3}{*}{ L091 } & \multirow{12}{*}{$7 "$} & 256.0 & $12.0 \times 13.0$ \\
\hline 2 & & & 257.0 & $12.0 \times 12.0$ \\
\hline 3 & & & 256.0 & $11.0 \times 12.0$ \\
\hline $\mathrm{Av}$ & & & 256.3 & 12.0 \\
\hline 4 & \multirow{3}{*}{ S992 } & & 193 & $12.0 \times 12.0$ \\
\hline 5 & & & 197 & $12.0 \times 12.0$ \\
\hline 6 & & & 222 & $12.0 \times 12.0$ \\
\hline \multicolumn{2}{|c|}{ Average } & & 204.0 & 12.0 \\
\hline 7 & \multirow{3}{*}{ Y971 } & & 184 & $11.0 \times 11.0$ \\
\hline 8 & & & 192 & $11.0 \times 11.0$ \\
\hline 9 & & & 195 & $11.0 \times 11.0$ \\
\hline \multicolumn{2}{|c|}{ Average } & & 190.3 & 11.0 \\
\hline
\end{tabular}
OF NORMAL TEMPERATURE

Table VI shows that, under normal conditions L091 loading explosives 4 1/2 "type perforating gun shells terrestrial analog equipment wear steel target average penetration depth of $256.3 \mathrm{~mm}$, the average pore diameter of the sleeve $12.0 \mathrm{~mm}$, compared to the S992-based perforation steel Target wearing dark charge $25.3 \%$ performance increase, perforated shells steel target compared to Y971-based charge to wear dark performance increase $36.7 \%$.

\section{B. Pendtrating target in condition of $220^{\circ} \mathrm{C} / 100 \mathrm{~h}$}

On the $220^{\circ} \mathrm{C} / 100 \mathrm{~h}$ high temperature of conditions, it is done that the simulation assembly gun will penetrate steel target. The heating and temperature measurement test device shown in Fig .7, Figure 8 shows the results of the effect of the test chart, the test results shown in Table VI.
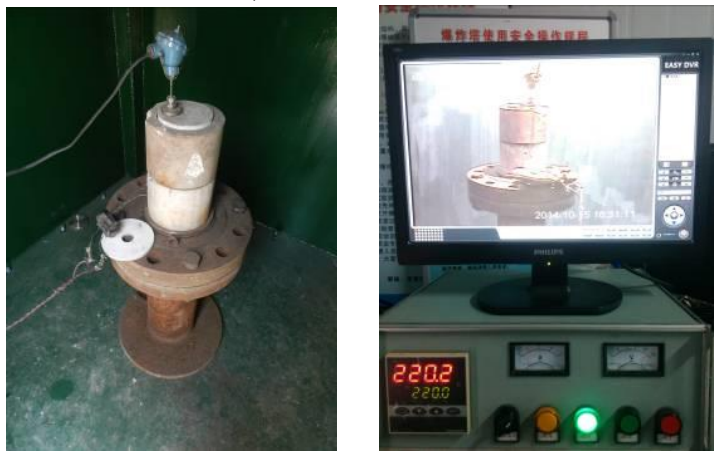

Figure 7. Devices of testing 


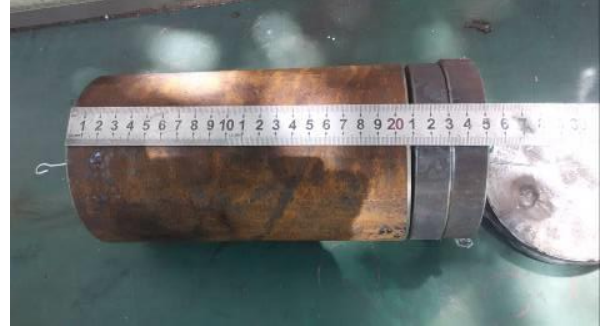

Figure 8. Testing results of penetrating target

TABLE VII. RESULTS OF PENDTRATING TARGET IN CONDITION OF $220^{\circ} \mathrm{C} / 100 \mathrm{H}$

\begin{tabular}{|c|c|c|c|c|}
\hline Sample & Powder & $\begin{array}{l}\text { casing } \\
\text { pipe }\end{array}$ & $\begin{array}{c}\text { Penetrating/ } \\
\text { mm }\end{array}$ & $\begin{array}{c}\text { Pore size of } \\
\text { casing } \\
\text { pipe } / \mathrm{mm}\end{array}$ \\
\hline 1 & \multirow{3}{*}{ L091 } & \multirow{3}{*}{$7 "$} & 254.0 & $12.0 \times 13.0$ \\
\hline 2 & & & 255.0 & $12.0 \times 12.0$ \\
\hline 3 & & & 255.0 & $11.0 \times 12.0$ \\
\hline \multicolumn{3}{|c|}{ Average } & 254.7 & 12.0 \\
\hline
\end{tabular}

Obtained from Table VII, on $220^{\circ} \mathrm{C} / 100 \mathrm{~h}$ of condition, the average penetration depth of steel target is $254.7 \mathrm{~mm}$ by shaped charge of assembly $41 / 2$ "type perforating gun, the average pore diameter of casing pipe $12.0 \mathrm{~mm}$.

\section{Penetrating API targets in condition of $220^{\circ} \mathrm{C}$ $/ 2 \mathrm{~h} / 20 \mathrm{Mpa}$}

In the high-temperature performance of the laboratory temperature $220^{\circ} \mathrm{C} / 2 \mathrm{~h}$, under pressure $20 \mathrm{Mpa}$ conditions to simulate loaded gun through API cylindrical concrete target test, the test assembly shown in Fig .9, the test results are shown in Table VIII, test results, see Fig .10.

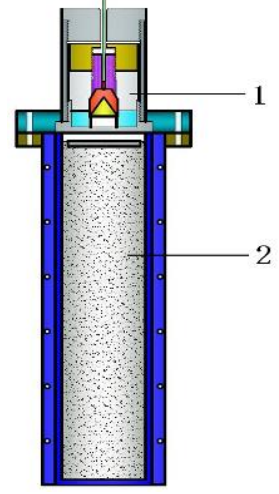

1--Perforator; 2-Target of API beton

Figure 9. Schematic diagtams of testing device

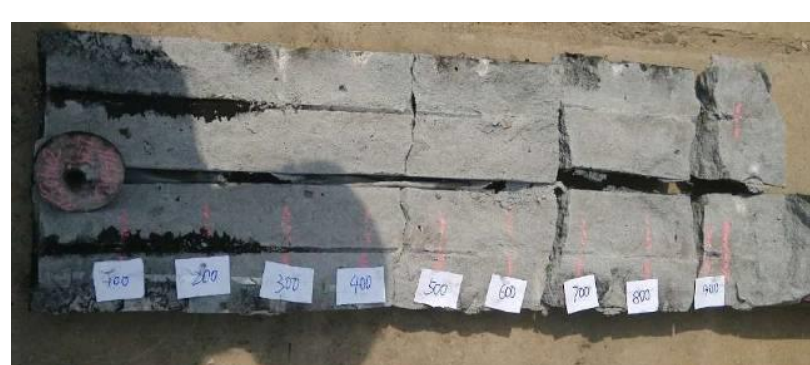

Figure 10. results of testing
TABLE VIII. RESULTS OF PENETRATING API TARGETS IN CONDITION OF $220^{\circ} \mathrm{C} / 2 \mathrm{H} / 20 \mathrm{MPA}$

\begin{tabular}{|c|c|c|c|c|}
\hline Sample & Powder & $\begin{array}{c}\text { casing } \\
\text { pipe }\end{array}$ & $\begin{array}{c}\text { Penetrating/ } \\
\mathbf{m m}\end{array}$ & $\begin{array}{c}\text { Pore size of } \\
\text { casing } \\
\text { pipe/mm }\end{array}$ \\
\hline 1 & \multirow{2}{*}{ L091 } & $7 "$ & 920 & $13.4 \times 13.6$ \\
\cline { 1 - 3 } 2 & & 925 & $13.3 \times 13.5$ \\
\hline \multicolumn{3}{|c|}{ Average } & 922.5 & 13.6 \\
\hline
\end{tabular}

Obtained from Table VIII, on $220^{\circ} \mathrm{C} / 2 \mathrm{~h} / 20 \mathrm{Mpa}$ of condition, the average penetration depth of API concrete target is $922.5 \mathrm{~mm}$ by shaped charge of assembly $41 / 2$ "type perforating gun, the average pore diameter of casing pipe $13.6 \mathrm{~mm}$.

\section{Results and Discussion}

Compared the data in Table VI with in Table VII, the depths of holes shaped in the steel targets by shaped charges under normal temperature and $220^{\circ} \mathrm{C} / 100 \mathrm{~h}$ were $256.3 \mathrm{~mm}$ and $254.7 \mathrm{~mm}$.Thus after high-temperature environments, the penetrating depth of steel target fell by 0.62 percent, a small decline, indicating the good heat resistance of the mixing explosives L091.

\section{CONCLUSION}

Through the safety testing of LLM-105 explosive performance related and the performance testing of mixed explosive LLM-105 with 4 1/2 "type of perforating charge, the following conclusions can be obtained.

(1) The thermal performance of LLM-105 is better, the highest exothermic decomposition temperature can reach $360.02^{\circ} \mathrm{C}$; flame sensitivity is $0 \%$. The result shows that LLM-105 has excellent heat resistance.

(2) LLM-105 explosive with low mechanical sensitivity, impact sensitivity is $42 \%$, the friction sensitivity is $16 \%$, LLM-105 had no obvious ignition phenomenon when the capacitor of $0.22 \mu \mathrm{F}$ is charged to $7.0 \mathrm{kV}$, electrostatic spark sensitivity is low, the $5 \mathrm{~s}$ delay explosion temperature of LLM-105 is $387^{\circ} \mathrm{C}$. Visiblely LLM-105 is an insensitive, high safety explosive.

(3)Compared to L091, S992, Y971 as the main charge perforator ground simulation load $41 / 2$ "gun performance testing, test results show that: the steel target average penetration depth of the $41 / 2$ " charge loaded L091 improved $25.3 \%$ than the charge loaded S992, and 36.7\% than the charge loaded Y971 under the normal temperature condition. Visiblely, LLM-105 is a high-energy and heat resistant explosive.

(4)The steel target average penetration depth of the 4 $1 / 2$ " charge loaded mixed LLM105 is $256.3 \mathrm{~mm}$ in normal temperature environment, $254.7 \mathrm{~mm}$ in the temperature of $220^{\circ} \mathrm{C} / 100 \mathrm{~h}$. The API columnar concrete targets average penetration depth is $922.5 \mathrm{~mm}$ under $220{ }^{\circ} \mathrm{C} / 2 \mathrm{~h} / 20 \mathrm{MPa}$ conditions, that LLM-105 explosive has high energy, vobvious effect of perforating charges application, it can use in the ultra-high temperature wells, and has safe, reliable, stable performance.

\section{REFERENCES}

[1] Pagoria P.F.,Mitchell A.R.,Schmidt R.D.,et al. Synthesis scale-up and experimental testing of LLM-105 Proceedings.1998 Insensitive 
Munitions and Energrtic Materials Technology Symposium.San Diego:1998.

[2] Tran T D,. "Characterization of 2,6-diamino-3,5-diniteopyrazine-1oxide(LLM-105)as an insensitive high explosive material" CA. Proceedings of 33rd International Annual Conference on ICT.Karlsruhe:ICT,2002.

[3] Tarver C M,Urtiew P A,Tran T D,et al. "Sensitivity of LLM-105." Energetic Materials, vol. 2,2005, pp:183-203.

[4] Weese $\mathrm{R}$ K,Burham A K,Turner H C,et al. "Physical characterization of RX-55-AE-5 a formulation of 97.5\% LLM-105 and $2.5 \%$ Viton A." CA. Proceeding of 33rd Annual Confence of NATA.CA:NATA,2005.

[5] LI Hai-bo,CHENG,Bi-bo,LI,Hong-zhen, et al.Synthesis of 2, 6Diamino-3 ,5-dinitropyrazine -1-oxide". Chinese Journal of Organic Chemistry, 2007, pp:112-115.

[6] GUO Feng-bo,LIU Yu-cun,LIU Deng-cheng, et al. "Optimization of the Synthetical Craft of 2,6-Diamino-3,5-Dinitropyrazine-1-
Oxide".Chinese Journal of Explosive\&Propellants, vol.1, 2006, pp:42-46.

[7] Robert D. Chapman, William S. Wilson, Joho W. Fronabarger,et al. Prospects of fused polycyclic nitroazines as thermally insensitive energetic materials. Thermochimica Acta, 2002, pp:229-243.

[8] D. M. Hoffman, K. T. Lorenz, B. Cunningham, F. Gaglilardi. "Formulaition and Mechanical Properties of LLM-105 PBXs," CA: Karlsruhe, Germany, June 27, 2008.

[9] Frank Garcia, Kevin S. Vandersall, Craig M. Tarver, Paul "A Urtiew. Shock initiation experiments on the LLM-105 explosive $\mathrm{RX}-55-\mathrm{AA}$ at $25^{\circ} \mathrm{C}$ and $150{ }^{\circ} \mathrm{C}$ with ignition and growth modeling. " CA,Kohala Coast,HI, United States, 2007..

[10] Adam Parker, Robert P. Claridge, Javid Hamid. Particle size modification of thermally stable secondary exploxives for IM applicaitions. Propellants, Explosives,Pyrotechnics, vol.1, 2008. pp:55-59. 